\section{The association between lumican gene polymorphisms and high myopia}

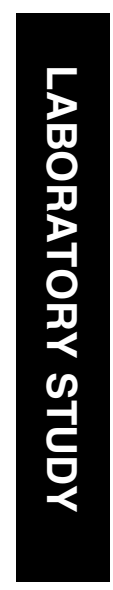

\begin{abstract}
Purposes Lumican (LUM) is one of the major extracellular matrix components of the sclera. Increasing evidence suggests that changes in the structure and composition of the sclera are major factors in regulating scleral integrity and axial elongation of the eye, as in myopia. Patients and methods Patients $(n=182$; age range, 17-24 years) were with a myopic spherical equivalent (SE) $>6.5$ diopters (D) and the control group comprised individuals ( $n=78$; age range, $17-25$ years) were with a myopic SE $<0.5 \mathrm{D}$. The DNA fragments were separated by horizontal electrophoresis on $3 \%$ agarose gels. The forward primer was labelled with a $5^{\prime}$ FAM and the reaction products were detected using a 3100 Genetic Analyzer.
\end{abstract}

Results The polymorphisms detected in this study were LUM c.601, LUM -59, LUM -628, and $L U M-1554$. Moreover, the haplotype distributions of $\mathrm{Ht1}(\mathrm{C} / \mathrm{A} / \mathrm{CC} / \mathrm{T}), \mathrm{Ht} 2(\mathrm{C} / \mathrm{A} /-/ \mathrm{T})$, $\mathrm{Ht} 3$ (T/A/CC/C), Ht4 (T/-/CC/T), Ht5 (T/-/CC/C), and $\mathrm{Ht} 6(\mathrm{~T} /-/-\mathrm{C})$ of these polymorphisms were compared between the two groups. The haplotype frequencies of $\mathrm{Ht} 1, \mathrm{Ht} 2, \mathrm{Ht} 5$, and Ht6 differed significantly between the two groups $\left(P=2.08 \times 10^{-5}\right.$, odds ratio (OR): 2.19, 95\% confidence interval (CI): 1.52-3.15; $P=2.2 \times 10^{-5}$, OR: $0.39,95 \%$ CI: $0.25-0.61$; $P=2.7 \times 10^{-5}$, OR: $0.36,95 \%$ CI: $0.22-0.59$; $P=3.7 \times 10^{-5}$, OR: $4.71,95 \%$ CI: $2.12-10.5$, respectively).

Conclusions These observations suggest that the four polymorphisms of the LUM promoter contribute to the pathogenesis of high myopia. Understanding the functions of LUM in myopia helps us design new methods in treating and preventing myopia.

Eye (2010) 24, 1093-1101; doi:10.1038/eye.2009.254; published online 11 December 2009

Keywords: extracellular matrix; genetic polymorphism; haplotype; lumican; myopia; sclera

H-J Lin ${ }^{1,2,3}$, L Wan ${ }^{2,3,4}$, Y Tsai ${ }^{3}$, W-C Chen ${ }^{2,5}$, S-W Tsai ${ }^{6}$ and F-J Tsai ${ }^{2,3}$

\section{Introduction}

The prevalence of myopia varies by country and by ethnic group, reaching as high as 70-90\% in some Asian populations, whereas occurring at $30-40 \%$ in Europe and North America and 10-20\% in Africa. ${ }^{1}$ According to epidemiological evidence, the prevalence of myopia is increasing, especially in Asian populations. ${ }^{2}$ Simple myopia can be corrected with spectacles or contact lenses, whereas 'high' myopia is often associated with potentially blinding conditions, such as retinal detachment, macular degeneration and glaucoma. ${ }^{3}$ The prevalence of pathological myopia has been estimated to be 1-3\% in population-based studies. ${ }^{4}$ In addition to the visual disability, there is a profound economic cost to society. Many studies have suggested that myopia is a complex disease with multiple causes, including the interaction of multiple genes with environment. ${ }^{5}$ Therefore, to understand myopia, it is necessary to apply the equation that genes plus the environment is equal to the outcome. ${ }^{5}$ Evidence that supports the idea that myopia and refractive errors are in large part genetically determined comes from twin studies and studies of refractive errors in parents and their children. ${ }^{6,7} \mathrm{~A}$ well-conducted study showed that refractive errors are much more strongly correlated in monozygotic twins than in dizygotic twins. ${ }^{7}$ In this study, we attempted to investigate the correlation between gene polymorphisms and the high myopia.

The sclera is external to the choroids, retinal pigment epithelium and anterior layers of the retina; it is a layer of viscoelastic connective tissue consisting of flattened fibroblasts embedded in an extracellular matrix and provides the structural framework defining the shape and axial length of the eye. ${ }^{8,9}$ As the development of high myopia involves the anterior-posterior enlargement of the eye, ${ }^{8,9}$
${ }^{1}$ Department of Ophthalmology, China Medical University Hospital, Taichung, Taiwan

${ }^{2}$ Department of Medical Genetics, China Medical University Hospital, Taichung, Taiwan

${ }^{3}$ School of Chinese Medicine, College of Chinese Medicine, China Medical University, Taichung, Taiwan

${ }^{4}$ Department of Biotechnology, Asia University, Taichung, Taiwan

${ }^{5}$ Graduate Institute of Integrated Medicine, College of Chinese Medicine, China Medical University, Taichung, Taiwan

Institute of Environmental Health, College of Public Health, National Taiwan University, Taipei, Taiwan

Correspondence: F-J Tsai and L Wan, Department of Medical Genetics and Pediatrics, China Medical University Hospital, No. 2, Yuh-Der Road, Taichung 404, Taiwan

Tel: + 886422052121 ext 2041;

Fax: + 886422033295 .

E-mail: d0704@

www.cmuh.org.tw

Received: 5 March 2009 Accepted in revised form: 3 September 2009 Published online: 11 December 2009 
the extension of sclera is one of the major aetiologies or outcomes of myopia. The major extracellular matrix components of the fibrous mammalian sclera are collagens types I and III and members of the small leucine rich proteoglycan (SLRP) family, which includes decorin, biglycan, lumican (LUM), and fibromodulin. ${ }^{10,11}$ The development of high myopia involves anteriorposterior enlargement of the eye and scleral thinning. ${ }^{8}$ Alterations in any of these extracellular matrix components are likely to lead to changes in scleral shape, which in turn could affect visual acuity, as the axial length of the eye is a major component in determining ocular refraction. ${ }^{12,13}$ In these extracellular matrix components of the fibrous mammalian sclera, we selected LUM as a candidate gene to study the genetic predisposition of high myopia. LUM, a member of the SLRP family, is a keratan sulphate proteoglycan originally identified in cornea, but present in a variety of connective tissues in which it presumably regulates collagen fibril formation and organization. LUM contained a core protein as a central region and surrounded by leucine rich repeats flanked by disulfide-bonded terminal domains. ${ }^{14,15}$ LUM regulates collagen fibril structure for optimal functioning of connective tissues. A recent mouse knockout study implicated that LUM was functional candidate gene for high myopia. ${ }^{16}$ LUM deficiency alone increased mean fibril diameter and had a profound effect on collagen fibril structure. ${ }^{16}$ Moreover, Young et al ${ }^{17}$ had identified a familial high myopia (MYP3) locus on 12q21.2-22. LUM is mapped within the chromosome 12q21-q23 MYP3 interval. ${ }^{18}$ Regardless of tacking the function of LUM or genetic map of the LUM into consideration, LUM is an important candidate gene for high myopia.

Myopia is a highly prevalent, complex phenotype involving genetic and environmental factors. To see whether the LUM polymorphisms were correlated with high myopia in Taiwanese Chinese, a group of high myopia patients, as well as a control group, test using polymerase chain reaction-restriction fragment length polymorphism (PCR-RFLP) to reveal the correlation of gene frequency between control subjects and patients with high myopia.

\section{Materials and methods}

\section{Patients}

From February to November 2004, we measured the refractive error in 3000 volunteers. All of the participants were medical students, unrelated, and Taiwan-born Han Chinese. Patients enrolled in this study also met specific criteria: age 16-25 years (mean age of $18 \pm 3.2$ years), male-to-female ratio of 1.8:1.0, and visual acuity with distance correction of $0.2 \log$ MAR (20/32) or better. Refractive error was measured in diopters (D) and determined by the mean spherical equivalent (SE) of the two eyes of each individual after administering one drop of cycloplegic drug (1\% mydriacyl, Alcon, Berlin). Individuals with myopia \&leq; $-6.5 \mathrm{D}$ (both eyes) were included in the study group and those with myopia $<0.5 \mathrm{D}$ and hyperopia $<1.0 \mathrm{D}$ (both eyes) were included in the control group (Table 1). The patients with astigmatism greater than myopic astigmatism $0.75 \mathrm{D}$ were excluded from the study, as it would change the results of SE. Our study was reviewed by the ethics committee and informed consent was obtained from all patients and control subjects. A comprehensive ophthalmic examination and blood collection were performed. The study was performed according to the tenets of the Declaration of Helsinki for research involving human subjects. None of the participants had known ocular disease, insult such as a history of retinopathy, prematurity, neonatal problems, or genetic disease, and/or connective tissue disorders associated with myopia, such as Strickler or Marfan syndromes. Clinical examination included visual acuity, refraction error, slit lamp examination, ocular movements, intraocular pressure, and fundoscopy. Patients with organic eye disease, a history or evidence of intraocular surgery, history of cataract, glaucoma, retinal disorders, or laser treatment were excluded. As with all data collection procedures, auto-refraction

Table 1 Characteristics of the study subjects and the partial correlation between spherical equivalent and other ocular components

\begin{tabular}{lccc}
\hline Characteristics & Control $(S D) \mathrm{n}=78$ & Cases $(S D) \mathrm{n}=182$ & All subjects (SD) $\mathrm{n}=260$ \\
\hline Age, mean (SD), year & $18(2.9)$ & $18(3.4)$ & $18(3.2)$ \\
Female, number (\%) & $33(35.1 \%)$ & $70(35.9 \%)$ & $103(35.6 \%)$ \\
SE, mean (SD), D & $0.02(0.32)$ & $-8.83(2.5)$ & $-4.5(4.8)$ \\
AXL, mean (SD), mm & $23.56(0.78)$ & $26.8(1.8)$ & $24.8(2.5)$ \\
CD, mean (SD), D & $43.5(0.9)$ & $44.2(1.9)$ & $43.8(1.5)$ \\
ACD, mean (SD), mm & $3.56(0.25)$ & $3.88(0.33)$ & $3.62(0.3)$ \\
LT, mean (SD), mm & $3.8(0.65)$ & $4.0(0.58)$ & $3.9(0.6)$ \\
\hline
\end{tabular}

Abbreviations: ACD, anterior chamber depth; AXL, axial length; CD, cornea diopter; LT, lens thickness; SE, spherical equivalent. 
(Auto-refractor/auto-keratometer [ARK 700A;

Nikon, Tokyo, Japan]) was conducted on both eyes by experienced optometrists who were trained and certified on study protocols. Refractive data, sphere (s), negative cylinder, and axis measurements were analysed by calculating SE refractive error.

\section{Genotype determinations}

Genomic DNA was extracted from whole blood samples after a standard protocol of digestion by proteinase $\mathrm{K}$ and purification with phenol-chloroform. The LUM gene was amplified by PCR and the DNA fragments were subjected to restriction enzyme digestion. PCR reactions were carried out in a total volume of $50 \mu \mathrm{l}$, containing $50 \mathrm{ng}$ genomic DNA, 2-6 pmole of each primer, $1 \times$ Taq polymerase buffer $\left(1.5 \mathrm{~mm} \mathrm{MgCl}_{2}\right)$, and 0.25 units of AmpliTaq DNA polymerase (Applied Biosystems, Froster City, CA, USA). The amplification protocol and restriction enzyme used to determine the genotype are listed in Table 2. Preventive contamination measures were taken by including a PCR reaction mixture without DNA (negative control) in each run of amplification. The DNA fragments were separated by horizontal electrophoresis on 3\% agarose gels, stained with ethidium bromide and photographed under ultraviolet lights. Data were analysed by ABI prism GeneMapper Version 3.0 software. We checked four candidate genetic polymorphisms in LUM; they included LUM c.601, promoter $-59 \mathrm{CC} /$ - polymorphism, promoter $-628 \mathrm{~A} /-$ (no del A/del A) polymorphism promoter, and promoter $-1554 \mathrm{~T} / \mathrm{C}$ polymorphism (Table 3). The PCR product

Table 2 Genetic polymorphisms in LUM

\begin{tabular}{|c|c|c|c|}
\hline Set & Primer and PCR condition & PCR product & $\begin{array}{l}\text { Restriction enzyme } \\
\text { cutting site }\end{array}$ \\
\hline $\begin{array}{l}\text { c. } 601 \mathrm{~T}>\mathrm{C} \\
\mathrm{rs} 17853500\end{array}$ & $\begin{array}{l}\text { F 5'-CCACTTCCCAAATCTCTGGA- } 3^{\prime} \text { R } 5^{\prime} \text {-TTTAATGGAGCCAGATGCAA-3' } \\
95^{\circ} \times 5 \mathrm{~min}, 95^{\circ} \times 30 \mathrm{~s} \text { and } 60^{\circ} \times 30 \mathrm{~s}\end{array}$ & $447+108 \mathrm{bp}$ & Msp I \\
\hline $\begin{array}{l}-59 \mathrm{CC} /- \\
\mathrm{rs} 3832846\end{array}$ & $\begin{array}{l}\text { F 5'-ACACCACAAGATCCCCACAATGAC- } 3^{\prime} \text { FAM labelled R } 5^{\prime} \text {-AAAGCAG } \\
\text { ATGCACTATGGACAAGA- } 3^{\prime} 95^{\circ} \times 5 \mathrm{~min}, 95^{\circ} \times 30 \mathrm{~s} \text { and } 60^{\circ} \times 30 \mathrm{~s}\end{array}$ & $173 \mathrm{bp}$ & - \\
\hline $\begin{array}{l}-628 \mathrm{~A} /- \\
\mathrm{rs} 17018757\end{array}$ & $\begin{array}{l}\text { F 5'-GAATGCTCTCCCCAAGTAAGG-3' R } 5^{\prime} \text {-CAGGAAAACGCAAATGAAC } \\
\text { AGA-3' } 95^{\circ} \times 5 \mathrm{~min}, 95^{\circ} \times 30 \mathrm{~s} \text { and } 60^{\circ} \times 30 \mathrm{~s}\end{array}$ & $118+198 b p$ & HpyCH4V \\
\hline $\begin{array}{l}-1554 \mathrm{~T} / \mathrm{C} \\
\mathrm{rs} 3759223\end{array}$ & $\begin{array}{l}\text { F 5'-ATGTATGAAATTTAAAGGAAGAA- } 3^{\prime} \text { R } 5^{\prime} \text {-ATGCTATGTATTAATTTTGA } \\
\text { GTGT- } 3^{\prime} 95^{\circ} \times 5 \mathrm{~min}, 95^{\circ} \times 30 \mathrm{~s} \text { and } 60^{\circ} \times 30 \mathrm{~s}\end{array}$ & $275+230 \mathrm{bp}$ & psiE \\
\hline
\end{tabular}

$\mathrm{F}$ and $\mathrm{R}$ indicated forward and reverse primers, respectively. Numbering LUM gene is according to genebank accession no. BC007038 and promoter numbering is according to genebank accession no. AF239660. The ATG start codon was indicated as +1 position.

Table 3 The genotype distribution of polymorphism between the high myopia group and control subjects

\begin{tabular}{|c|c|c|c|c|c|c|c|c|c|c|}
\hline SNP & Genotype & Controls & Cases & $\begin{array}{c}\text { OR } \\
(95 \% C I)\end{array}$ & $\begin{array}{l}\text { P-value } / \\
\text { Cp-value }\end{array}$ & Allele & Controls & Cases & $\begin{array}{c}\text { OR } \\
(95 \% C I)\end{array}$ & $\begin{array}{l}\text { P-value }{ }^{\mathrm{a}} \\
\text { Cp-value }\end{array}$ \\
\hline $\begin{array}{l}\text { LUM c.601T >C } \\
\text { (S1) }\end{array}$ & $\begin{array}{c}\mathrm{n} \\
\mathrm{T} / \mathrm{T} \\
\mathrm{T} / \mathrm{C} \\
\mathrm{C} / \mathrm{C}\end{array}$ & $\begin{array}{cl} & 78 \\
36 & (46.1 \%) \\
41 & (53.6 \%) \\
1 & (1.3 \%)\end{array}$ & $\begin{aligned} & 182 \\
101 & (55.5 \%) \\
68 & (37.4 \%) \\
13 & (7.1 \%)\end{aligned}$ & $\begin{array}{l}1 \\
0.34-1.02 \\
0.59-36.69\end{array}$ & $0.028 / 0.112$ & $\begin{array}{l}\mathrm{n} \\
\mathrm{T} \\
\mathrm{C}\end{array}$ & $\begin{aligned} & 156 \\
& 113(72.4 \%) \\
& 43(27.6 \%)\end{aligned}$ & $\begin{aligned} & 364 \\
270 & (74.2 \%) \\
94 & (25.8 \%)\end{aligned}$ & $\begin{array}{l}1 \\
0.60-1.40\end{array}$ & $0.068 / 0.272$ \\
\hline $\begin{array}{l}\operatorname{LUM}-59 \mathrm{CC} /- \\
\text { (S2) }\end{array}$ & $\begin{array}{c}\mathrm{N} \\
\mathrm{CC} / \mathrm{CC} \\
\mathrm{CC} /- \\
-/-\end{array}$ & $\begin{array}{c}78 \\
35(44.9 \%) \\
6(7.7 \%) \\
37(47.4 \%)\end{array}$ & $\begin{array}{l}182 \\
87(47.8 \%) \\
17(9.3 \%) \\
78(42.9 \%)\end{array}$ & $\begin{array}{l}1 \\
0.42-3.13 \\
0.49-1.48\end{array}$ & $0.769 / 1$ & $\begin{array}{c}\mathrm{n} \\
\mathrm{CC} \\
-\end{array}$ & $\begin{array}{cl} & 156 \\
76 & (48.7 \%) \\
80 & (51.3 \%)\end{array}$ & $\begin{array}{cl} & 364 \\
191 & (52.5 \%) \\
173 & (47.5 \%)\end{array}$ & $\begin{array}{l}1 \\
0.60-1.25\end{array}$ & $0.432 / 1$ \\
\hline $\begin{array}{l}\text { LUM -628 A/- } \\
\text { (S3) }\end{array}$ & $\begin{array}{c}\mathrm{N} \\
-/- \\
\mathrm{A} /- \\
\mathrm{A} / \mathrm{A}\end{array}$ & $\begin{array}{c}78 \\
4(5.1 \%) \\
39(50.0 \%) \\
35(44.9 \%)\end{array}$ & \begin{tabular}{l}
\multicolumn{1}{c}{182} \\
$11(6.0 \%)$ \\
$73(40.1 \%)$ \\
$98(53.8 \%)$
\end{tabular} & $\begin{array}{l}1 \\
0.20-2.28 \\
0.30-3.41\end{array}$ & $0.353 / 1$ & $\frac{\mathrm{n}}{\mathrm{A}}$ & $\begin{array}{c}156 \\
47(30.1 \%) \\
109(69.9 \%)\end{array}$ & $\begin{aligned} & 364 \\
95 & (26.1 \%) \\
269 & (73.9 \%)\end{aligned}$ & $\begin{array}{l}1 \\
0.81-1.85\end{array}$ & $0.345 / 1$ \\
\hline $\begin{array}{l}\text { LUM -1554 T/C } \\
\text { (S4) }\end{array}$ & $\begin{array}{c}\mathrm{N} \\
\mathrm{G} / \mathrm{G} \\
\mathrm{A} / \mathrm{A} \\
\mathrm{A} / \mathrm{G}\end{array}$ & $\begin{array}{c}78 \\
3(3.8 \%) \\
41(52.6 \%) \\
35(44.9 \%)\end{array}$ & $\begin{array}{l}182 \\
13(7.1 \%) \\
74(40.7 \%) \\
95(52.2 \%)\end{array}$ & $\begin{array}{l}1 \\
0.11-1.55 \\
0.17-2.33\end{array}$ & $0.222 / 0.888$ & $\begin{array}{l}\mathrm{n} \\
\mathrm{G} \\
\mathrm{A}\end{array}$ & $\begin{array}{c}156 \\
47(30.1 \%) \\
109(69.9 \%)\end{array}$ & $\begin{array}{c}364 \\
100(27.5 \%) \\
264(72.5 \%)\end{array}$ & $\begin{array}{l}1 \\
0.75-1.72\end{array}$ & $0.538 / 1$ \\
\hline
\end{tabular}

${ }^{a}$ The $\chi 2$ test or Fisher's exact test was performed to obtain the $P$-value. The percentages of myopia and control with ht 1 were compared with the percentages of myopia and control without ht1. Statistical significance was considered as $P$-value $<0.05$.

${ }^{\mathrm{b}} \mathrm{C} p$-value, $P$-value corrected by Bonferroni correction. 




Figure 1 The LUM c.601 T>C polymorphic region was amplified by PCR, resulting in a digestible fragment in lane 1 $(447+108 \mathrm{bp})$, an un-digestible fragment in lanes 2 and 3 (555 bp) and a ' $\mathrm{C} / \mathrm{C}^{\prime}$ homozygote in lane 4.

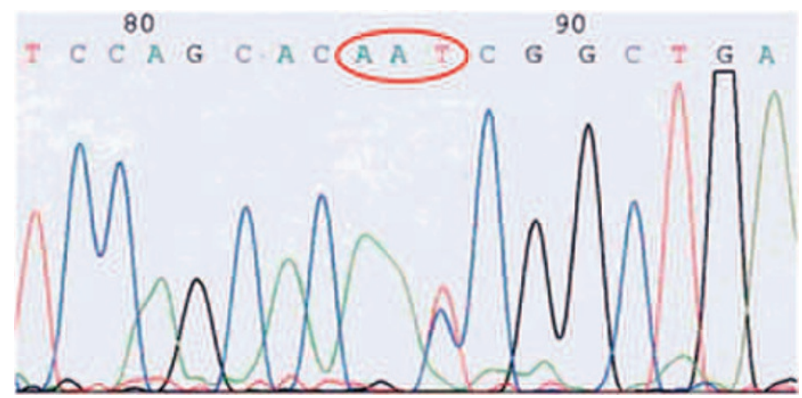

Figure 2 Arrow indicates the region of the LUM c.601 $T>C$ polymorphism that is located at the 169th nucleotide downstream the ATG start codon.

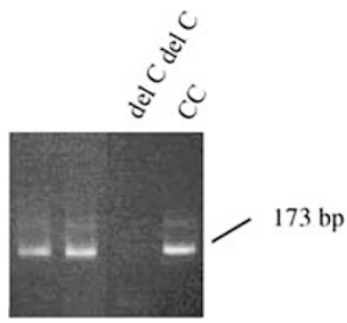

Figure 3 PCR-based restriction analysis of the LUM -59 CC/polymorphism. The polymorphic region was amplified by PCR, resulting in a $173 \mathrm{bp}$ DNA fragment.

of c.601 was digested with 10 units of Msp I. Restriction digest conditions were those recommended by the enzyme manufacturer (New England Biolabs, Mississauga, Ontario, Canada); the ' $T$ ' allele was $555 \mathrm{bp}$ and the ' $C$ ' allele was $447 \mathrm{bp}+108 \mathrm{bp}$ as shown in Figure 1 . The polymorphisms were also conformed by sequencing (Figure 2). For the $-59 \mathrm{CC} /$ - polymorphism, the forward primer was FAM labelled and a $173 \mathrm{bp}$ DNA fragment was generated and analysed by the 3100

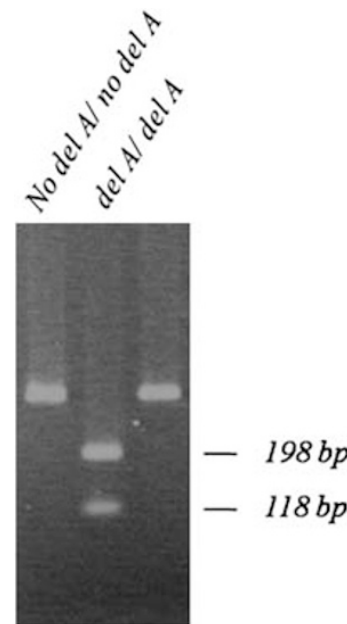

Figure 4 PCR-based restriction analysis of the LUM -628 (no del A/del A) polymorphism. The polymorphic region was amplified by PCR, resulting in an un-digestible fragment in lane 1 and line 3 (198 bp), and a digestible fragment in lane 2 $(118+80 \mathrm{bp})$.



Figure 5 PCR-based restriction analysis of the LUM -1544 $(T / C)$ polymorphism. The polymorphic region was amplified by PCR, resulting in an un-digestible fragment in lane 1 (275 bp), a digestible fragment in lane $2(230 \mathrm{bp})$ and a heterozygote in lane 3.

Genetic Analyzer (Applied Biosystems) (Figure 3). For the c. $-628 \mathrm{~A} /-$ polymorphism, the forward primer was FAM labelled; a 118 and 198 bp DNA fragment were generated (Figure 4). For the LUM $-1544 T / C$ polymorphism, the ' $T$ ' allele was $275 \mathrm{bp}$ and the ' $C$ ' allele was $230 \mathrm{bp}$ as shown in Figure 5. We also compared the relationship between the LUM haplotypes of these polymorphisms and the susceptibility to high myopia. Haplotypes were inferred from unphased genotype data using the Bayesian statistical method available in the software program Phase 2.1. All five single nucleotide polymorphisms (SNPs) were analysed with the Phase 2.1 
Table 4 Odds ratio and 95\% CI for the association between lum gene haplotypes and myopia

\begin{tabular}{|c|c|c|c|c|c|c|c|c|}
\hline Haplotype & -1554 & -628 & -59 & 601 & Patient (\%) & Control $(\%)$ & $P$-value $/ C p$-value $e^{\mathrm{b}}$ & Odds Ratio (95\% CI) \\
\hline Ht1 & $\mathrm{C}$ & $\mathrm{A}$ & $\mathrm{CC}$ & $\mathrm{T}$ & $437(60.03)$ & $126(40.38)$ & $2.08 \times 10^{-5} / 1.248 \times 10^{-4}$ & $2.19(1.52-3.15)$ \\
\hline Ht2 & $\mathrm{C}$ & A & - & $\mathrm{T}$ & $96(13.19)$ & $88(28.20)$ & $2.2 \times 10^{-5} / 1.32 \times 10^{-4}$ & $0.39(0.25-0.61)$ \\
\hline Ht3 & $\mathrm{T}$ & A & $\mathrm{CC}$ & C & $2(0.27)$ & $3(0.96)$ & $0.164 / 0.984$ & $0.21(0.02-2.35)$ \\
\hline $\mathrm{Ht} 4$ & $\mathrm{~T}$ & - & $\mathrm{CC}$ & $\mathrm{T}$ & $9(1.24)$ & $13(4.17)$ & $0.03 / 0.18$ & $0.3(0.09-0.95)$ \\
\hline Ht5 & $\mathrm{T}$ & - & $\mathrm{CC}$ & C & $62(8.52)$ & $69(22.12)$ & $2.7 \times 10^{-5} / 1.62 \times 10^{-4}$ & $0.36(0.22-0.59)$ \\
\hline Ht6 & $\mathrm{T}$ & - & - & C & $122(16.76)$ & $13(4.17)$ & $3.7 \times 10^{-5} / 2.22 \times 10^{-4}$ & $4.71(2.12-10.5)$ \\
\hline
\end{tabular}

Abbreviation: CI, confidence interval.

${ }^{\text {aThe }} \chi 2$ test or Fisher's exact test was performed to obtain the $P$-value. The percentages of myopia and control with ht 1 were compared with the percentages of myopia and control without ht1. Statistical significance was considered as $P$-value $<0.05$.

${ }^{\mathrm{b}} \mathrm{C} p$-value, $P$-value corrected by Bonferroni correction.

software. Insertion/deletion SNPs (-628 A/- and -59 $\mathrm{CC} /-$ ) were given numerical designations (insertion: 1 ; deletion: -1$).{ }^{19}$ We found that there were six haplotypes composed by the four polymorphisms we detected in the myopia and control groups (Table 4). We defined haplotype $1(\mathrm{Ht} 1)$ to haplotype $6(\mathrm{Ht} 6)$ as the alternative alleles of the LUM polymorphisms (Table 4).

\section{Statistical analysis}

Genotypes were obtained by direct counting with subsequent calculation of allele frequencies. Data were analysed using the $\chi 2$ test or Fisher's exact test and $P$-values were calculated using the Minitab program. A $P$-value $<0.05$ was considered significant. Adherence to the Hardy-Weinberg equilibrium (HWE) constant was tested using a $\chi 2$ test with a one degree of freedom. Odds ratios (OR) and the corresponding 95\% confidence intervals $(\mathrm{CI})$ were calculated with reference to the allele and genotype. Correction for multiple comparisons was carried out by Bonferroni correction. ${ }^{20} \mathrm{Next}$, all detected SNPs were assessed for HWE using the $\chi 2$ test. $^{21}$ For the SNPs found significant after multiple testing correction, stepwise logistic regression was used to determine whether any one of these SNPs could account for the effects of the other positive SNPs. STATA package (version 8.2; Stata Corp., College Station, TX, USA) was used to perform the stepwise logistic regression.

\section{Results}

The volunteers enrolled in this study were with age 16-25 years (mean age, $18 \pm 3.2$ years), male-to-female ratio of 1.8-1.0, mean axial length $24.8 \mathrm{~mm}$, and mean $\mathrm{SE}-4.5 \mathrm{D}$. There were no significant difference between the control and cases groups in age, gender, cornea diopter, anterior chamber depth, and lens thickness (Table 1). The study group comprised 182 patients with high myopia and the control group consisted of 78 individuals with normal eyes. PCR-RFLP and direct-sequencing analysis revealed three different genotypes of the LUM c.601 T > C genetic polymorphism: $T / T, C / T$, and $C / C$ (Figures 1 and 2). The genotype distributions of the LUM c.601 T >C polymorphism obtained from the patients and controls are shown in Table 3. The genotype frequencies of $T / T: T / C: C / C$ were 54.49: 37.36: $7.14 \%$, respectively, in the high myopia group and 46.15: $52.56: 1.28 \%$, respectively, in the control group. The allelic frequency of T: C was 74.18: $25.82 \%$, respectively, in the high myopia group and 72.44: $27.56 \%$ , respectively, in the control group. Before Bonferroni correction, there was a significant difference in genotype distribution of the LUM c.601 T >C polymorphism between high myopia patients and normal controls $(P=0.028)$ (Table 3$)$, but it was no more true after Bonferroni correction $(P=0.112)$ (Table 3$)$. Considering the LUM c.601 T>C polymorphism, high myopia patients had higher probability of the $T / T$ genotype than the $C / C$ or $C / T$ genotype. Nevertheless, there was no significant difference in the distribution of the $C$ allele and $T$ allele between the high myopia group and the normal control group $(P=0.812)$. That is, only when patients with ' $T T$ ' homozygote will increase the incidence of high myopia, but not found in patients only with ' $T$ ' allele. There were no significant differences in the genotype distributions or allele frequencies of the other LUM polymorphisms between the two groups (LUM promoter $-59 \mathrm{CC} /$ - polymorphism, $P=0.769 ;$ LUM c. $-628 \mathrm{~A} /-, P=0.353 ;$ LUM $-1544 \mathrm{~T} / \mathrm{C}$ polymorphism, $P=0.222$ ) (Table 3 ). Furthermore, some known polymorphisms in LUM were not found in our population after sequencing the genome of our candidates. In haplotype study, we compared the distributions of $\mathrm{Ht} 1(\mathrm{C} / \mathrm{A} / \mathrm{CC} / \mathrm{T}), \mathrm{Ht} 2(\mathrm{C} / \mathrm{A} /-/ \mathrm{T})$, Ht3 (T/A/CC/C), Ht4 (T/-/CC/T), Ht5 (T/-/CC/C), and Ht6 $(\mathrm{T} /-/-/ \mathrm{C})$ between the high myopia group and the control group and found that the distribution of Ht1, Ht2, Ht5, and Ht6 differed significantly different between the two groups $\left(P=2.08 \times 10^{-5}\right.$, OR: $2.19,95 \%$ CI: $1.52-3.15 ; P=2.2 \times 10^{-5}$, OR: $0.39,95 \%$ CI: $0.25-0.61$; 
Table 5 Tests the main effects of SNPs by stepwise logistic regression procedure

\begin{tabular}{lcc}
\hline Null model & Alternative model & P-value \\
\hline $\mathrm{S} 1+\mathrm{S} 2+\mathrm{S} 3+\mathrm{S} 4$ & $\mathrm{~S} 1+\mathrm{S} 3+\mathrm{S} 4$ & 0.9552 \\
$\mathrm{~S} 1+\mathrm{S} 2+\mathrm{S} 3+\mathrm{S} 4$ & $\mathrm{~S} 2+\mathrm{S} 3+\mathrm{S} 4$ & 0.9633 \\
$\mathrm{~S} 1+\mathrm{S} 2+\mathrm{S} 3+\mathrm{S} 4$ & $\mathrm{~S} 1+\mathrm{S} 2+\mathrm{S} 3$ & 0.2237 \\
$\mathrm{~S} 1+\mathrm{S} 2+\mathrm{S} 3+\mathrm{S} 4$ & $\mathrm{~S} 1+\mathrm{S} 2+\mathrm{S} 4$ & 0.4365 \\
\hline
\end{tabular}

Abbreviations: S1, LUM c.601T>C ; S2, LUM -59 CC/-; S3, LUM -628 A/-; S4, LUM -1554 T/C.

$P=2.7 \times 10^{-5}$, OR: $0.36,95 \%$ CI: $0.22-0.59 ; P=3.7 \times 10^{-5}$, OR: $4.71,95 \%$ CI: 2.12-10.5, respectively) (Table 4).

There was no significant difference in the distribution of Ht3 and HT4 between the two groups $(P=0.164$ and 0.03 , respectively) (Table 4 ). After Bonferroni correction, Ht1, Ht2, Ht5, and Ht6 still revealed significantly different between the two groups (Table 4). The frequencies of $\mathrm{Ht} 2$ and Ht5 were higher in the control than in the high myopia group; the frequencies Ht1 and Ht6 were higher in the high myopia group than in the control group.

A stepwise logistic regression procedure was used to detect which of the significant SNPs contributed to the main effects (Table 5). By the backwards procedure, eliminated S2 (LUM -59 CC/ -), S1 (LUM c.601T > C), S4 (LUM -1554 T/C), and S3 (LUM -628 A/-) (Table 5) from the model all did not have significant effect $(P=0.9952,0.9633,0.2237$, and 0.4365$)$. In conclusion, the stepwise regression procedure showed that none of the polymorphisms contributed the most significant main effect of LUM. The influences of LUM on myopia were the co-effects of all polymorphisms.

In the test of HWE of the polymorphisms, LUM -628 and LUM -1554 were of equilibrium with the $P$-values: 0.175 and 0.246 . The other two marks LUM c.601 and LUM -59 were out of equilibrium with the $P$-value: 0.005 and $1.3 \times 10^{-15}$.

\section{Discussion}

There were stronger correlations that would be expected by chance in a study of the correlation between refractive error in parents and siblings. ${ }^{22}$ Genetic studies of families with a history of high myopia have uncovered some polymorphisms and separate loci for high myopia, such as on chromosome $18 \mathrm{p}$ and $12 \mathrm{q}^{23,24}$ and in the myocilin,, ${ }^{25} \mathrm{TGF}^{26} \mathrm{PAX}^{27},{ }^{27}$ and COL1A1 genes. ${ }^{28}$ These polymorphisms indicate a genetic predisposition to the development of high myopia. However, these genes cannot be solely responsible for the development of myopia, particularly in the wide variability of the prevalence of myopia in different ethnic groups. ${ }^{23-29}$
The difficulty here is the uncertainty surrounding environmental influences and genetic factors.

In this study, we attempted to map myopia with SNPs. In addition, individuals with higher education levels have a higher prevalence of myopia than people in the general population, which is why students in medical school are chosen as candidates in this study. The control group composed by medical students might decrease the bias of environmental influence.

Gene-knockout studies in mice have shown that the LUM and fibromodulin genes may be candidate genes responsible for high myopia, because of increased axial length in double-null mice. However, Paluru et al ${ }^{30}$ suggested that the knockout study findings represented a false-positive result because of the 'hitchhiker gene effect': Adjacent altered genes influenced the phenotype rather than the implicated candidate genes. In a study by Paluru et $a l^{30}$, the MYP3 family was investigated and 10 affected individuals in these two pedigrees were screened. ${ }^{30}$ Wang et $a l^{31}$ also excluded the possibility of the association between high myopia and the LUM gene (rs3759223). However, case-control studies indicated that the SNP of the LUM gene may be a risk factor for the pathogenesis of high myopia in Han Chinese, English, and Finnish populations. To establish whether LUM gene polymorphisms are correlated with high myopia in a Taiwanese Chinese population, sequences spanning all three exons, intronexon boundaries and promoter regions were determined in 50 normal individuals. The four SNPs in this study were determined by DNA sequencing. Moreover, we observed that the frequencies of the haplotypes $\mathrm{Ht} 1$ (C/A/CC/T), Ht2 (C/A/-/T), Ht5 (T/-/CC/C), and Ht6 $(\mathrm{T} /-/-/ \mathrm{C})$ differed significantly between the two groups (Table 2). The Ht2 $(\mathrm{C} / \mathrm{A} /-/ \mathrm{T})$ and $\mathrm{Ht} 5$ (T/-/CC/C) haplotype occurred less common in the study group (13.19 and $8.52 \%$, individually) than in the control group (28.20 and $22.12 \%$ individually). The Ht2 and Ht5 haplotypes might have the functions in preventing the development of high myopia.

On the contrary, the Ht1 (C/A/CC/T) and Ht6 (T/-/-/C) haplotype occurred less common in control group than in myopia group (40.38 vs $60.03 \%$ and 4.17 vs $16.76 \%$, respectively) (Table 2). The Ht 1 and Ht 6 haplotypes increased the susceptibility of developing high myopia. The results of haplotype analysis did not change after Bonferroni correction (Table 2). In the stepwise logistic regression procedure, we observed that the LUM c.601, LUM -59, LUM -628, and LUM - 1554 co-contribute to the genetic background of high myopia and none of the polymorphisms played the main effect. Consequently, the action of LUM on high myopia was not a single gene effect, but it was the result of multiple genes' cooperation. The significance of ' $T / T$ ' homozygote 
of LUM c.601T > C became none after Bonferroni correction, the function of single genotype was not sufficient to effect the result.

To examine the genotyping error and to validate our findings, we repeated the genotyping analysis several times and obtained consistent results. Our sequences were mostly clean at baseline. Therefore, occurrence of genotyping errors in this study was kept to a minimum. In the HWE test, however, two out of the SNPs considered in our study were not in HWE. The deviations from HWE may indicate possible association with the myopia, which is also the sign indicating the presence of mutation. This disequilibrium seemed to be other support of the association of the polymorphisms in LUM with high myopia. Moreover, we try to trace the ancestry background of controls and patients. In Taiwanese, $85 \%$ are Minnan descendants, $5 \%$ of them are Hakka descendants and the remaining $10 \%$ are mixed population of Minnan, Hakka, and Canton descendants. According to the paper published in Hum Hered (2006) by Pan et al, ${ }^{32}$ they mentioned that on the SNP profiles in the major histocompatibility complex region (6p21.3) showed no significant difference among these groups, which indicate the homogeneous of the population in Taiwanese. Thus, population stratification should not produce in this study.

There were some studies about LUM from other study groups with diverse conclusions. Paluru et al ${ }^{30}$ studied on a total of 10 individuals with high myopia (average spherical refractive error was -16.13D) and were screened for sequence alterations in the LUM, with six primer pairs spanning intron-exon boundaries, and coding regions were designed for the three-exon $1804 \mathrm{bp}$ of LUM and no polymorphism segregated with high myopia was found. ${ }^{30}$ The diverse result from this study might be explained by racial differences. Furthermore, the polymorphisms inspected in their studies were different with us. (The polymorphisms, which they detected, were rs14987011, 14983585, 14984369, 14784146, 14979221, and 14979222; the polymorphisms, which we analysed, were rs17853500, rs3832846, rs17018757, and rs3759223.). Besides, there was a study cited last year by Majava et $a l^{33}$ that LUM (c.893-105G > A) revealed significant differences between English patients and control subjects. Majava et $a l^{33}$ found that the LUM gene may have a protective function against high myopia. Nevertheless, after we detected the sequencing, the LUM (c.893-105G > A) polymorphisms analysed in the study by Majava et $a l^{33}$ are not prevalent in our population. This might be due to ethic variation. Although the results were different, these also supported the hypothesis that myopia was a complex disease and that multiple genes were involved in the pathogenesis of the myopia. In another study, Wang et $a^{31}$ also evaluated SNPs in the LUM gene in Taiwanese Chinese. Wang et al ${ }^{31}$ reported significant differences in the polymorphism rs3759223 C > T of the LUM gene between patients and control subjects. The polymorphism rs3759223 C-> T of the LUM gene is the same polymorphism as the c. -1554 polymorphism in this study. However, we did not find a significant difference in the distribution of the c. -1554 polymorphism between the two groups $(P=0.222)$. The discrepancy between the findings in the two studies might be due to differences in inclusion criteria. The patients in the study by Wang et al ${ }^{31}$ had refractive errors of myopia $10.00 \mathrm{D}$ or more, whereas the patients in our group had refractive errors of myopia 6.5 D or more. The mean age of the population in their study was $34.4 \pm 15.2$ years and that in our study was $18 \pm 3.2$ years. The control group from their study comprised individuals with refractive errors ranging from myopia 0.5 to $1.5 \mathrm{D}$, whereas in our study, the control subjects had refractive errors less than myopia $0.5 \mathrm{D}$. In Wang's study, ${ }^{31}$ myopia $>10 \mathrm{D}$ were selected, which could be more genetic factor; however, the population of this study was younger freshmen and high myopia just over than $6 \mathrm{D}$ that could be more environmental effect than genetic factor in such high myopic country; in contrast, control group could be more genetic factor. In short, the polymorphism c. -1554 might be a good predictor of very high myopia (myopia $>10 \mathrm{D}$ ), but is not a suitable marker for high myopia group (myopia $>6 \mathrm{D}$ ). Furthermore, the population in our high myopia group $(n=182)$ was larger than that in the study of Wang et $a l^{31}(n=120)$, but the population of the control group of our study group $(n=78)$ was less than that in the study of Wang et $\mathrm{al}^{31}(n=137)$; the differences in the numbers of subjects studied may also contribute to the discrepancy between the findings in the two studies. On the basis of these data, we could not make any conclusion about the function of LUM -1554 and high myopia. Further studies about LUM -1554 are needed to verify the function of it. In the future, we intend to replicate this analysis in a separate population group, such as in a non-student population. We also plan to analyse the genotypes of the parents of the highly myopic subjects to elude the possibility of the bias and intend to analyse the data from the 3000 subjects across the spectrum of refractive error to understand the relationship between LUM and severity of myopia.

LUM is expressed in the extracellular matrix of the sclera and has been shown to be associated with the development of myopia, ${ }^{34}$ but the studies of the locus of LUM, chromosome12q21-q23, still did not fully 
resolve the relationship of LUM and high myopia. ${ }^{30}$ In our study, we screened 3000 volunteers and selected 178 individuals with high myopia. There were significant difference in halpotype distributions between the study and control groups. Complex diseases, such as diabetes, cancer, asthma, and arthritis, are probably caused by subtle changes in multiple genes combined with environmental and life-style factors. Investigating the genetics of common and complex disorders, such as myopia, remains as one of the great challenges in human genetics. Myopia is considered as a complex and multigenic disease involving several overlapping signalling pathways, each one mediated by a group of distinct genetic profiles. Therefore, studying the genetic polymorphisms of related mechanisms of myopia can help further clarify the relationship between genetics and myopia. The interaction of these extracellular matrixes may influence the result of sceral modelling. The presence of a relatively high concentration of LUM core protein in the human sclera suggests multiple functions for LUM in the scleral matrix. ${ }^{34}$ In addition to transcriptional regulation, post-translational modification also may have a function in controlling bioactivity. As noted above, the SNPs were selected by DNA-sequencing results. As for the transcription factor binding site in those SNPs, we used Mapper search engine to predict the possible effects. ${ }^{35}$ Only rs3759223 showed the possibility of influencing the binding of transcription factors, whereas others either had no effect on transcription factor binding (rs3832846) or no transcription factor binding to this region (rs17018757). TATA box binding protein will bind to $-1554 \mathrm{~T}$, but not $-1554 \mathrm{C}$, which may influence the rate of transcription complex formation and initiation of transcription. Genes further upstream and downstream of LUM will also need to be investigated, as it is likely that a number of genes will form the genetic background in individuals with myopia, on which environmental factors will act, to give rise to myopia.

\section{Summary}

\section{What was known before}

- Lumican (LUM) is one of the major extracellular matrix components of the sclera. Increasing evidence suggests that changes in the structure and composition of the sclera are major factors in regulating scleral integrity and axial elongation of the eye, as in myopia. Our aim was to examine the association between myopia and the polymorphisms within the LUM gene.

What this study adds

- Polymorphisms of the LUM promoter contribute to the pathogenesis of high myopia.

\section{Conflict of interest}

The authors declare no conflict of interest.

\section{Acknowledgements}

This study was supported by grants from the China Medical University Hospital (DMR-93-45) and from the National science council, Taiwan (NSC 96-2628-B-039-002-MY3).

\section{References}

1 Chow YC, Dhillon B, Chew PT, Chew SJ. Refractive errors in Singapore medical students. Singapore Med J 1990; 31: 472-473.

2 Wang TJ, Chiang TH, Wang TH, Lin LL, Shih YF. Changes of the ocular refraction among freshmen in National Taiwan University between 1988 and 2005. Eye 2009; 23(5): 1168-1169.

3 Celorio JM, Pruett RC. Prevalence of lattice degeneration and its relation to axial length in severe myopia. Am J Ophthalmol 1991; 111(1): 20-23.

4 Vongphanit J, Mitchell P, Wang JJ. Prevalence and progression of myopic retinopathy in an older population. Ophthalmology 2002; 109: 704-711.

5 Feldkamper M, Schaeffel F. Interactions of genes and environment in myopia. Dev Ophthalmol 2003; 37: 34-49.

6 Lyhne N, Sjolie AK, Kyvik KO, Green A. The importance of genes and environment for ocular refraction and its determiners: a population based study among 20-45 year old twins. Br J Ophthalmol 2001; 85: 1470-1476.

7 Hammond CJ, Snieder H, Gilbert CE, Spector TD. Genes and environment in refractive error: the twin eye study. Invest Ophthalmol Vis Sci 2001; 42: 1232-1236.

8 Tkatchenko AV, Walsh PA, Tkatchenko TV, Gustincich S, Raviola E. Form deprivation modulates retinal neurogenesis in primate experimental myopia. Proc Natl Acad Sci USA 2006; 103: 4681-4686.

9 Siegwart Jr JT, Norton TT. Selective regulation of MMP and TIMP mRNA levels in tree shrew sclera during minus lens compensation and recovery. Invest Ophthalmol Vis Sci 2005; 46: 3484-3492.

10 Dunlevy JR, Rada JA. Interaction of lumican with aggrecan in the aging human sclera. Invest Ophthalmol Vis Sci 2004; 45: 3849-3856.

11 Rada JA, Achen VR, Penagonda S, Mount BA. Proteoglycan composition in the human sclera during growth and aging. Invest Ophthalmol Vis Sci 2000; 41: 1639-1648.

12 McBrien NA, Lawlor P, Gentle A. Scleral remodeling during the development of and recovery from axial myopia in tree shrew. Invest Ophthalmol Vis Sci 2000; 41: 3713-3719.

13 McBrien NA, Gentle A. Role of the sclera in the development and pathological complications of myopia. Prog Retin Eye Res 2003; 22: 307-338.

14 Funderburgh JL, Funderburgh ML, Mann MM, Conrad GW. Arterial lumican: properties of a corneal-type keratan sulfate proteoglycan from bovine aorta. J Biol Chem 1991; 266: 24773-24777.

15 Iozzo RV. The family of the small leucine-rich proteoglycans: key regulators of matrix assembly and cellular growth. Crit Rev Biochem Mol Biol 1997; 32: 141-174. 
16 Chakravarti S, Paul J, Roberts L, Chervoneva I, Oldberg A, Birk DE. Ocular and scleral alterations in gene-targeted lumican-fibromodulin double-null mice. Invest Ophthalmol Vis Sci 2003; 44: 2422-2432.

17 Young TL, Ronan SM, Alvear AB, Wildenberg SC, Oetting WS, Atwood LD et al. A second locus for familial high myopia maps to chromosome 12q. Am J Hum Genet 1998; 63: 1419-1424.

18 Grover J, Chen XN, Korenberg JR, Roughley PJ. The human lumican gene: organization, chromosomal location, and expression in articular cartilage. J Biol Chem 1995; 270: 21942-21949.

19 Chugh R, Wathen JK, Maki RG, Benjamin RS, Patel SR, Myers PA et al. Phase II multicenter trial of imatinib in 10 histologic subtypes of sarcoma using a Bayesian hierarchical statistical model. J Clin Oncol 2009; 27: 3148-3153.

20 Lam DS, Lee WS, Leung YF, Tam PO, Fan DS, Fan BJ et al. TGFbeta-induced factor: a candidate gene for high myopia. Invest Ophthalmol Vis Sci 2003; 44: 1012-1015.

21 Falconer DS, Mackay TFC. Introduction to Quantitative Genetics, 4th edn. Essex (UK): Longman, 1996.

22 Teikari J, O’Donnell J, Kaprio J, Koskenvuo M. Genetic and environmental effects on oculometric traits. Optom Vis Sci 1980; 66: 594-599.

23 Young TL, Ronan SM, Alvear AB, Wildenberg SC, Oetting WS, Atwood LD et al. A second locus for familial high myopia maps to chromosome 12q. Am J Hum Genet 1998; 63: 1419-1424.

24 Farbrother JE, Kirov G, Owen MJ, Pong-Wong R, Haley CS, Guggenheim JA. Linkage analysis of the genetic loci for high myopia on $18 \mathrm{p}, 12 \mathrm{q}$, and $17 \mathrm{q}$ in 51 UK families. Invest Ophthalmol Vis Sci 2004; 45: 2879-2885.

25 Tang WC, Yip SP, Lo KK, Ng PW, Choi PS, Lee SY et al. Linkage and association of myocilin (MYOC) polymorphisms with high myopia in a Chinese population. Mol Vis 2007; 13: 534-544.
26 Lin HJ, Wan L, Tsai Y, Tsai YY, Fan SS, Tsai CH et al. The TGFbeta1 gene codon 10 polymorphism contributes to the genetic predisposition to high myopia. Mol Vis 2006; 12: 698-703.

27 Hewitt AW, Kearns LS, Jamieson RV, Williamson KA, van Heyningen V, Mackey DA. PAX6 mutations may be associated with high myopia. Ophthalmic Genet 2007; 28: 179-182.

28 Inamori $\mathrm{Y}$, Ota $\mathrm{M}$, Inoko $\mathrm{H}$, Okada $\mathrm{E}$, Nishizaki R, Shiota $\mathrm{T}$ et al. The COL1A1 gene and high myopia susceptibility in Japanese. Hum Genet 2007; 122: 151-157.

29 Paluru P, Ronan SM, Heon E, Devoto M, Wildenberg SC, Scavello G et al. New locus for autosomal dominant high myopia maps to the long arm of chromosome 17 Invest Ophthalmol Vis Sci 2003; 44: 1830-1836.

30 Paluru PC, Scavello GS, Ganter WR, Young TL. Exclusion of lumican and fibromodulin as candidate genes in MYP3 linked high grade myopia. Mol Vis 2004; 10: 917-922.

31 Wang IJ, Chiang TH, Shih YF, Hsiao CK, Lu SC, Hou YC et al. The association of single nucleotide polymorphisms in the $5^{\prime}$-regulatory region of the lumican gene with susceptibility to high myopia in Taiwan. Mol Vis 2006; 12 852-857.

32 Pan WH, Fann CS, Wu JY, Hung YT, Ho MS, Tai TH et al. Han Chinese cell and genome bank in Taiwan: purpose design and ethical considerations. Hum Hered 2006; 61: 27-30.

33 Majava M, Bishop PN, Hägg P, Scott PG, Rice A, Inglehearn $\mathrm{C}$ et al. Novel mutations in the small leucine-rich repeat protein/proteoglycan (SLRP) genes in high myopia. Hum Mutat 2007; 28: 336-344.

34 Siegwart Jr JT, Strang CE. Selective modulation of scleral proteoglycan mRNA levels during minus lens compensation and recovery. Mol Vis 2007; 13: 1878-1886.

35 Marinescu VD, Kohane IS, Riva A. MAPPER: a search engine for the computational identification of putative transcription factor binding sites in multiple genomes. BMC Bioinformatics 2005; 6: 79. 